\title{
Clinical Study \\ Relationship between Plasma Leptin Level and Chronic Kidney Disease
}

\author{
Anoop Shankar, ${ }^{1}$ Shirmila Syamala, ${ }^{2}$ Jie Xiao, ${ }^{1}$ and Paul Muntner ${ }^{3}$ \\ ${ }^{1}$ Department of Community Medicine, West Virginia University School of Medicine, P.O. Box 9190, \\ Morgantown, WV 26506-9190, USA \\ ${ }^{2}$ Department of Medicine, West Virginia University School of Medicine, Morgantown, WV 26506, USA \\ ${ }^{3}$ Department of Epidemiology, University of Alabama at Birmingham, Birmingham, AL 35294, USA
}

Correspondence should be addressed to Anoop Shankar, ashankar@hsc.wvu.edu

Received 28 September 2011; Accepted 2 March 2012

Academic Editor: Jochen Reiser

Copyright ( $) 2012$ Anoop Shankar et al. This is an open access article distributed under the Creative Commons Attribution License, which permits unrestricted use, distribution, and reproduction in any medium, provided the original work is properly cited.

\begin{abstract}
Background. Leptin is an adipose tissue-derived hormone shown to be related to several metabolic, inflammatory, and hemostatic factors related to chronic kidney disease. Recent animal studies have reported that infusion of recombinant leptin into normal rats for 3 weeks fosters the development of glomerulosclerosis. However, few studies have examined the association between leptin and CKD in humans. Therefore, we examined the association between plasma leptin levels and CKD in a representative sample of US adults. Methods. We examined the third National Health and Nutrition Examination Survey participants $>20$ years of age $(n=5820,53.6 \%$ women). Plasma leptin levels were categorized into quartiles $(\leq 4.3 \mathrm{Fg} / \mathrm{L}, 4.4-8.7 \mathrm{Fg} / \mathrm{L}, 8.8-16.9 \mathrm{Fg} / \mathrm{L}$, $>16.9 \mathrm{Fg} / \mathrm{L}$ ). CKD was defined as a glomerular filtration rate of $<60 \mathrm{~mL} / \mathrm{min} / 1.73 \mathrm{~m}^{2}$ estimated from serum creatinine. Results. Higher plasma leptin levels were associated with CKD after adjusting for age, sex, race/ethnicity, education, smoking, alcohol intake, body mass index (BMI), diabetes, hypertension, and serum cholesterol. Compared to quartile 1 of leptin (referent), the odds ratio (95\% confidence interval) of CKD associated with quartile 4 was 3.31 (1.41 to 7.78); P-trend $=0.0135$. Subgroup analyses examining the relation between leptin and CKD by gender, BMI categories, diabetes, and hypertension status also showed a consistent positive association. Conclusion. Higher plasma leptin levels are associated with CKD in a representative sample of US adults.
\end{abstract}

\section{Introduction}

Leptin is an adipose tissue-derived hormone that has been shown to be related to several metabolic, inflammatory, and hemostatic factors involved in the development of hypertension and cardiovascular disease [1]. Experimental animal studies suggest that higher leptin levels may cause hyperglycemia, elevations in blood pressure (mediated through increased sympathetic activity), and renal dysfunction [2]. In rat models, leptin has been shown to induce natriuresis [3] which may in turn result in an increase in arterial pressure so as to maintain sodium and water balance [4]. Leptin has also been shown to serve as a cofactor of TGF-beta activation, promote renal endothelial cell proliferation, and potentially may play a role in renal glomerulosclerosis [5-7]. Recent studies have reported that infusion of recombinant leptin into normal rats for 3 weeks fosters the development of focal glomerulos 4.clerosis [5]. However, few human studies have examined the putative association between plasma leptin levels and chronic kidney disease (CKD) in humans. In this context, we examined the independent relation between plasma leptin levels and CKD in a multiethnic sample of US adults, after adjusting for main confounding factors.

\section{Methods}

The current study is based on data from the Third National Health and Nutrition Examination Survey (NHANES III). 
Detailed description of NHANES III study design and methods are available elsewhere [8-13]. In brief, NHANES III included a stratified multistage probability sample representative of the civilian noninstitutionalized US population. Selection was based on counties, blocks, households, and individuals within households and included the oversampling of non-Hispanic blacks and Mexican Americans in order to provide stable estimates of these groups. Subjects were required to sign a consent form before their participation, and approval was obtained from the Human Subjects Committee in the US Department of Health and Human Service. Secondary data analysis was approved by the West Virginia University Institutional Review Board.

The sample included in the current analysis consisted of participants aged greater than 20 years who were randomly assigned to complete an examination in the morning after an overnight fast. Plasma leptin levels were measured in 6415 of these participants. We further excluded participants with self-reported cardiovascular disease $(n=434)$, missing serum creatinine $(n=60)$ or who were missing data $(n=$ 101) on covariates included in the multivariable model, including systolic or diastolic blood pressure, body mass index (BMI), or cholesterol levels. This resulted in 5820 participants (53.6\% women).

2.1. Main Outcome of Interest: Presence of Chronic Kidney Disease. Serum creatinine was measured using the Jaffe kinetic alkaline picrate method performed on a Roche Hitachi 737 analyzer [13]. The laboratory coefficient of variability ranged from $0.2 \%$ to $1.4 \%$. Serum creatinine values in NHANES III were calibrated to the standard creatinine values from the Cleveland Clinic Foundation (CCF) laboratory who used a Roche coupled enzymatic assay method that was traceable to an isotope dilution mass spectrometric method using the following Deming regression equation: Standard Creatinine in $\mathrm{mg} / \mathrm{dL}=0.960 \times$ NHANES measured serum creatinine (in mg/dL)-0.184 [14]. Glomerular filtration rate (eGFR) was estimated from serum creatinine using the 4variable Modification of Diet in Renal Disease (MDRD) study equation as follows: $\mathrm{eGFR}=175 \times$ (serum creatinine in $\mathrm{mg} / \mathrm{dL})^{-1.154} \times(\text { age in years })^{-0.203} \times(0.742$ if female $)$ $\times(1.21$ if black) [15]. CKD was defined as an eGFR of $<60 \mathrm{~mL} / \mathrm{min} / 1.73 \mathrm{~m}^{2}$, consistent with National Kidney Foundation Kidney Disease Outcomes Quality Initiative $(\mathrm{KDOQI}) \geq$ Stage 3 chronic kidney disease [16].

2.2. Exposure Measurements. Age, gender, race/ethnicity, smoking status, alcohol intake (g/day), level of education, history of diabetes and oral hypoglycemic intake or insulin administration, and antihypertensive medication use were assessed using standardized questionnaires. Individuals who had not smoked $\geq 100$ cigarettes in their lifetimes were considered never smokers; those who had smoked $\geq 100$ cigarettes in their lifetimes were considered former smokers if they answered negatively to the question "Do you smoke now?" and current smokers if they answered affirmatively.
Using height and weight measured during the study examination, body mass index (BMI) was calculated as weight in kilograms divided by height in meters squared.

Rigorous procedures with quality control checks were used in blood collection and details about these procedures are provided in the NHANES Laboratory/Medical Technologists Procedures Manual [8, 11]. Measurement of plasma leptin was performed by Linco Research, Inc., St. Louis, Mo, USA. The assay was a radioimmunoassay (RIA) with a polyclonal antibody raised in rabbits against highly purified recombinant human leptin. The minimum detectable concentration of the assay was $0.5 \mathrm{Fg} / \mathrm{L}$ leptin, and the limit of linearity was $100 \mathrm{Fg} / \mathrm{L}$. Recovery of leptin added to serum is $99-104 \%$ over the linear range of the assay. The RIA agrees reasonable well with rough quantification by Western blot. Within- and between-assay CVs ranged from $3.4 \%$ to $8.3 \%$ and from $3.6 \%$ to $6.2 \%$, respectively $[11,12]$.

Serum total cholesterol was measured enzymatically at the Johns Hopkins Lipid Laboratory. Serum glucose was measured using the modified hexokinase method at the University of Missouri Diabetes Diagnostic Laboratory. Diabetes was defined based on the guidelines of the American Diabetes Association as a serum glucose $\geq 126 \mathrm{mg} / \mathrm{dL}$ after fasting for a minimum of 8 hours, a serum glucose $\geq 200 \mathrm{mg} / \mathrm{dL}$ for those who fasted $<8$ hours before their NHANES visit, a glycosylated hemoglobin value $\geq 6.5 \%$, or a selfreported current use of oral hypoglycemic medication or insulin. Seated systolic and diastolic blood pressures were measured using a mercury sphygmomanometer according to the American Heart Association and Seventh Joint National Committee (JNC7) recommendations [17]. Up to 3 measurements were averaged for systolic and diastolic pressures. Participants were considered to have hypertension if they reported current blood pressure-reducing medication use and/or had systolic blood pressure $\geq 140 \mathrm{~mm} \mathrm{Hg}$ and/or diastolic blood pressure $\geq 90 \mathrm{~mm} \mathrm{Hg}$ [17].

2.3. Statistical Analysis. Plasma leptin was analyzed both as a continuous variable as well as a categorical variable. For the analysis as a continuous variable, leptin values were log transformed (base e) as a result of their skewed distribution. Using the distribution present in the NHANES III population, we categorized plasma leptin level into quartiles $(\leq 4.3 \mathrm{Fg} / \mathrm{L}, 4.4-8.7 \mathrm{Fg} / \mathrm{L}, 8.8-16.9 \mathrm{Fg} / \mathrm{L},>16.9 \mathrm{Fg} / \mathrm{L})$. The multivariable-adjusted odds ratio [(OR) (95\% confidence interval (CI)] of CKD associated with leptin quartile was calculated with the lowest quartile as the referent, using logistic regression models. Odds ratios were calculated initially after age and sex adjustment and subsequently after additional adjusting for race/ethnicity (non-Hispanic whites, non-Hispanic blacks, Mexican Americans, and others), education categories (below high school, high school, above high school), smoking (never smoker, former smoker, current smoker), alcohol intake (continuous), BMI (continuous), diabetes mellitus (absent, present), hypertension (absent, present), and total serum cholesterol (continuous). Trends in the OR of CKD across increasing plasma leptin category were determined by modeling median within-quartile leptin 
level as a continuous variable. To examine the dose-response relationship of the observed association between plasma leptin level and CKD without linearity assumptions, we used flexible nonparametric logistic regression employing the generalized additive modeling approach $(\mathrm{R}$ system for statistical computing, available from Comprehensive R Archive Network [http://www.cran.r-project.org/]) to calculate odds ratio of CKDs mellitus, adjusting for all covariates in the multivariable model; the predicted odds ratio of CKD was then plotted against increasing leptin levels (on the log scale). Previous studies have shown that serum leptin levels are associated with increased systemic inflammation as measured by C-reactive protein levels [18], hyperglycemia [12], high insulin levels [19], and increased systolic blood pressure [20], factors that have also been shown to be associated with $\mathrm{CKD}[17,21,22]$. Therefore, in a supplementary analysis, to examine if the observed association between plasma leptin and CKD was explained by C-reactive protein levels, fasting insulin, glucose levels, or systolic blood pressure, we adjusted for these variables in the multivariable-adjusted model. Sample weights [9] that account for the unequal probabilities of selection, oversampling, and nonresponse were applied for all analyses using SUDAAN (version 8.0; Research Triangle Institute, Research Triangle Park, NC) and SAS (version 9.2; SAS Institute, Cary, NC) software; Standard errors (SE) were estimated using the Taylor series linearization method.

\section{Results}

Table 1 presents the characteristics of the study population included in the current analysis. Overall, this study included a broad age range, multiethnic sample of Americans with an approximately equal number of men and women. The mean eGFR of the study participants was $94 \mathrm{~mL} / \mathrm{min} / 1.73 \mathrm{~m}^{2}$, and $3.5 \%$ had CKD.

Table 2 presents the association between quartile of plasma leptin and CKD. A positive association between higher leptin quartiles and CKD was present in the age, sexadjusted model as well as the multivariable model. When analyzed as a continuous variable after log transformation, a positive association was present between leptin and CKD.

Table 3 presents the association between plasma leptin levels and CKD within subgroups defined by gender, BMI categories, and diabetes and hypertension. Overall, the association between leptin and CKD was consistently present within these subgroups. Although some of the ORs failed to reach conventional levels of statistical significance due to limited sample size and therefore statistical power, tests for interaction were not statistically significant (each $P>0.10$ for all stratified analyses).

When we employed nonparametric models to graphically examine the dose-response relationship between plasma leptin levels and CKD without linearity assumptions involved in traditional regression models, we observed an overall positive association between plasma leptin and CKD, consistent with the results in Tables 1,2, and 3. However, there was a steeper association with CKD for plasma leptin levels $>16 \mathrm{Fg} / \mathrm{L}$ (Figure 1).
TABLE 1: Characteristics of the study population $(n=5820)$.

\begin{tabular}{|c|c|}
\hline Characteristics & $\begin{array}{c}\text { Mean or } \\
\text { percentage } \pm \\
\text { standard error }\end{array}$ \\
\hline Age, years & $43.1 \pm 0.5$ \\
\hline Women, \% & $53.6 \pm 0.9$ \\
\hline \multicolumn{2}{|l|}{ Race-ethnicity, \% } \\
\hline Non-Hispanic whites & $77.1 \pm 1.5$ \\
\hline Non-Hispanic blacks & $10.3 \pm 0.7$ \\
\hline Mexican Americans & $5.1 \pm 0.5$ \\
\hline Other & $7.6 \pm 1.0$ \\
\hline \multicolumn{2}{|l|}{ Education categories, \% } \\
\hline Less than high school & $21.5 \pm 1.1$ \\
\hline High school & $34.3 \pm 1.1$ \\
\hline More than high school & $44.2 \pm 1.5$ \\
\hline \multicolumn{2}{|l|}{ Smoking, \% } \\
\hline Never & $48.3 \pm 1.0$ \\
\hline Former & $25.0 \pm 0.7$ \\
\hline Current & $26.7 \pm 1.0$ \\
\hline Current alcohol drinker, \% & $56.1 \pm 1.7$ \\
\hline Body mass index, $\mathrm{kg} / \mathrm{m}^{2}$ & $26.5 \pm 0.2$ \\
\hline Diabetes mellitus, \% & $5.0 \pm 0.4$ \\
\hline Hypertension, \% & $28.4 \pm 1.1$ \\
\hline Total cholesterol, mg/dL & $203.0 \pm 0.9$ \\
\hline Glomerular filtration rate, $\mathrm{mL} / \mathrm{min} / 1.73 \mathrm{~m}^{2}$ & $95.6 \pm 0.7$ \\
\hline Chronic kidney disease, $\% *$ & $3.6 \pm 0.3$ \\
\hline Glucose, $\mathrm{mg} / \mathrm{dL}$ & $98.8 \pm 0.4$ \\
\hline Insulin, $\mathrm{uU} / \mathrm{mL}$ & $10.4 \pm 0.2$ \\
\hline Systolic blood pressure, $\mathrm{mmHg}$ & $120.8 \pm 0.5$ \\
\hline Diastolic blood pressure, $\mathrm{mmHg}$ & $73.8 \pm 0.2$ \\
\hline C-reactive protein, $\mathrm{mg} / \mathrm{dL}$ & $0.38 \pm 0.01$ \\
\hline
\end{tabular}

*Defined as estimated glomerular filtration rate $<60 \mathrm{~mL} / \mathrm{min} / 1.73 \mathrm{~m}^{2}$.

In a supplementary analysis, to examine if the observed association between leptin and CKD was explained by Creactive protein, a marker of inflammation, or fasting insulin or glucose levels, or systolic blood pressure, we additionally adjusted for these variables to the multivariable-adjusted model. The positive association between leptin and CKD was attenuated, but still present. Compared to quartile 1 of plasma leptin (referent), the multivariable OR (95\% CI) of CKD was 1.31 (0.70 to 2.44) in quartile $2,1.22$ (0.57 to 2.62 ) in quartile 3 , and 2.72 (1.14 to 6.48$)$ in quartile $4 ; P$ trend $=0.0475$.

\section{Discussion}

In a multi-ethnic, population-based sample of US adults, we found that higher plasma leptin levels were positively associated with CKD. This association appeared to be independent of confounders such as age, race-ethnicity, education, BMI, diabetes, and hypertension and appeared to be consistently present in both men and women. Furthermore, the observed 
TABLE 2: Association between plasma leptin level and prevalence of chronic kidney disease (CKD).

\begin{tabular}{|c|c|c|c|c|}
\hline $\begin{array}{l}\text { Plasma leptin } \\
\text { level }\end{array}$ & $N$ & $\begin{array}{c}\text { CKD } \\
\text { weighted \% }\end{array}$ & $\begin{array}{l}\text { Age, sex-adjusted odds } \\
\text { ratio ( } 95 \% \text { confidence } \\
\text { interval) } \\
\end{array}$ & $\begin{array}{c}\text { Multivariable-adjusted } \\
\text { odds ratio ( } 95 \% \text { confidence } \\
\text { interval) }{ }^{*}\end{array}$ \\
\hline $\begin{array}{l}\text { Quartile } 1(\leq 4.3 \\
\text { Fg/L) }\end{array}$ & 1453 & 1.8 & 1 (referent) & 1 (referent) \\
\hline $\begin{array}{l}\text { Quartile } 2 \\
(4.4-8.7 \mathrm{Fg} / \mathrm{L})\end{array}$ & 1541 & 3.2 & $1.42(0.80$ to 2.52$)$ & $1.35(0.73$ to 2.52$)$ \\
\hline $\begin{array}{l}\text { Quartile } 3 \\
(8.8-16.9 \mathrm{Fg} / \mathrm{L})\end{array}$ & 1464 & 3.5 & $1.40(0.74$ to 2.62$)$ & $1.34(0.63$ to 2.87$)$ \\
\hline $\begin{array}{l}\text { Quartile } 4 \\
(>16.9 \mathrm{Fg} / \mathrm{L})\end{array}$ & 1452 & 6.3 & 3.25 (1.61 to 6.55$)$ & $3.31(1.41$ to 7.78$)$ \\
\hline$P$-trend & & & 0.0019 & 0.0135 \\
\hline $\begin{array}{l}\text { Log- } \\
\text { transformed } \\
\text { leptin } \\
\end{array}$ & 5820 & 3.6 & $1.57(1.23$ to 2.01$)$ & $1.74(1.27$ to 2.38$)$ \\
\hline
\end{tabular}

TABLE 3: Association between plasma leptin level and chronic kidney disease (CKD), by subgroups.

\begin{tabular}{|c|c|c|c|}
\hline Subgroups of interest & $\begin{array}{c}\text { No. at } \\
\text { risk }\end{array}$ & $\begin{array}{c}\text { CKD } \\
\text { weighted \% }\end{array}$ & $\begin{array}{l}\text { Multivariable-adjusted odds ratio of CKD associated } \\
\text { with log-leptin (95\% confidence interval)* }\end{array}$ \\
\hline \multicolumn{4}{|r|}{ 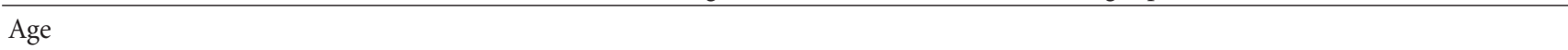 } \\
\hline$<60$ & 4324 & 0.9 & $2.06(1.01$ to 4.20$)$ \\
\hline$\geq 60$ & 1496 & 15.7 & $1.36(1.01$ to 1.83$)$ \\
\hline \multicolumn{4}{|l|}{ Gender } \\
\hline Men & 2627 & 2.8 & $1.43(0.96$ to 2.12$)$ \\
\hline Women & 3193 & 4.3 & 1.77 (1.09 to 2.88$)$ \\
\hline \multicolumn{4}{|l|}{ Race-ethnicity, \% } \\
\hline Non-Hispanic whites & 2403 & 3.9 & $1.63(1.10$ to 2.41$)$ \\
\hline Non-Hispanic blacks & 1615 & 2.5 & $3.31(1.86$ to 5.90$)$ \\
\hline $\begin{array}{l}\text { Mexican Americans, } \\
\text { others }\end{array}$ & 1802 & 2.5 & $1.40(0.80$ to 2.45$)$ \\
\hline \multicolumn{4}{|l|}{ Body mass index (BMI) } \\
\hline $\mathrm{BMI}<25 \mathrm{~kg} / \mathrm{m}^{2}$ & 2273 & 2.9 & $1.38(0.62$ to 3.07$)$ \\
\hline $\begin{aligned} & 25 \mathrm{~kg} / \mathrm{m}^{2} \leq \mathrm{BMI} \\
< & 30 \mathrm{~kg} / \mathrm{m}^{2}\end{aligned}$ & 2058 & 3.6 & $2.44(1.48$ to 4.04$)$ \\
\hline $\mathrm{BMI} \geq 30 \mathrm{~kg} / \mathrm{m}^{2}$ & 1489 & 4.9 & $3.30(1.91$ to 5.70$)$ \\
\hline \multicolumn{4}{|l|}{ Diabetes } \\
\hline Absent & 5358 & 3.2 & $1.70(1.23$ to 2.35$)$ \\
\hline Present & 462 & 10.1 & $1.41(0.42$ to 4.73$)$ \\
\hline \multicolumn{4}{|l|}{ Hypertension } \\
\hline Absent & 3908 & 1.6 & $1.42(0.66$ to 3.07$)$ \\
\hline Present & 1912 & 8.6 & $1.73(1.20$ to 2.49$)$ \\
\hline
\end{tabular}

*Adjusted for age (years), sex (female, male), race-ethnicity (non-Hispanic whites, non-Hispanic blacks, Mexican Americans, others), education categories (<high school, high school, > high school), smoking (never, former, current), current alcohol intake (absent, present), body mass index (normal, overweight, obese), diabetes (absent, present), hypertension (absent, present), serum total cholesterol (mg/dL), glucose ( $\mathrm{mg} / \mathrm{dL})$, insulin $(\mathrm{uU} / \mathrm{mL})$ and C-reactive protein $(\mathrm{mg} / \mathrm{dL})$, except the stratifying variable. 


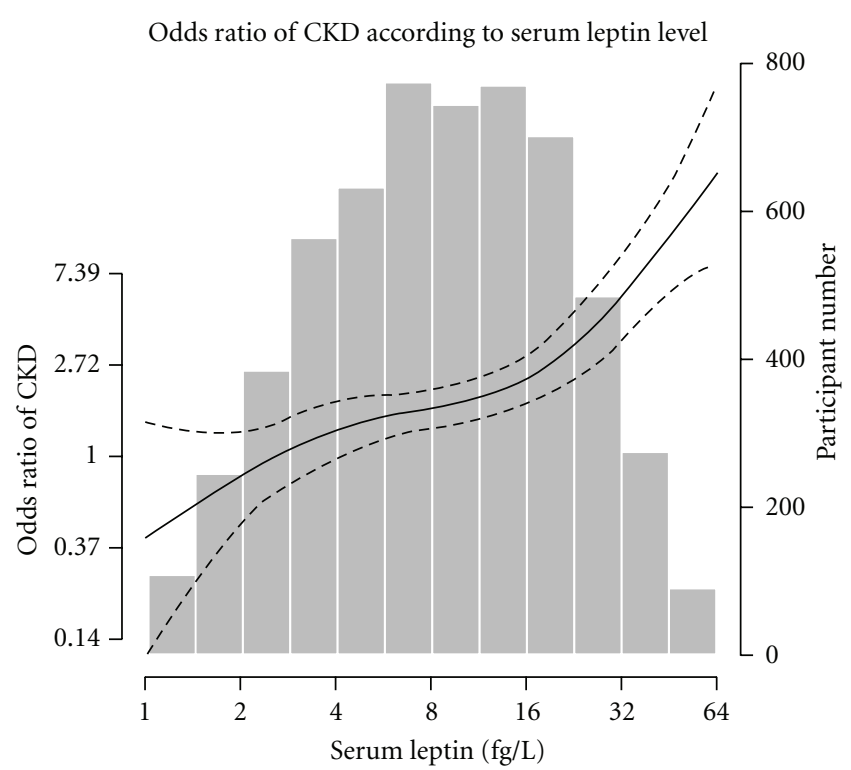

FIgURE 1: Multivariable-adjusted odds ratio of chronic kidney disease (CKD) according to plasma leptin level (Fg/L). Solid thick line represents the predicted odds of CKD from nonparametric logistic regression; dashed lines, 95\% confidence limits for the nonparametric logistic regression estimates. The nonparametric logistic regression was adjusted for age (years), sex (men, women), race-ethnicity (non-Hispanic whites, non-Hispanic blacks, Mexican Americans, others), education categories ( $<$ high school, high school, >high school), smoking (never, former, current), body mass index (normal, overweight, obese), diabetes (absent, present), and serum total cholesterol $(\mathrm{mg} / \mathrm{dL})$. The median value of quartile 1 of leptin $(1.285 \mathrm{Fg} / \mathrm{L})$ was used as the referent category to calculate odds ratios. $X$ axis: plasma leptin level (fg/L) plotted in log scale, $Y 1$ axis: predicted odds ratio of CKD plotted in log scale, $Y 2$ axis: participant number for each serum plasma leptin level.

association between plasma leptin levels and CKD was present even after adjusting for C-reactive protein and fasting insulin levels, suggesting an association between this adipokine and CKD that is independent of these factors.

Several lines of recent evidence suggest that an association between leptin and CKD is plausible. This includes the role of leptin in activating the sympathetic nervous system and causing chronic elevations in blood pressure and renal dysfunction [2], inducing natriuresis [3] which may result in an increase in arterial pressure so as to maintain sodium and water balance [4], serving as a cofactor of TGF-beta activation, promoting renal endothelial cell proliferation, and subsequent glomerulosclerosis [5-7]. It was recently shown that, in rats, infusion of recombinant leptin caused the development of focal glomerulosclerosis [5]. Also, leptin is also reported to be related to insulin resistance [23] and high C-reactive protein levels [24], both of which have been shown to be related to CKD $[21,25]$.

There are a few studies in the literature for comparison. A previous study conducted among women with type 1 diabetes reported that plasma leptin levels are independently related to reduced renal function [26]. In a study from South Africa conducted among approximately 300 black subjects, Okpechi et al. reported that plasma leptin levels were inversely related to eGFR [27]. In another study, common polymorphisms in the LEP gene were found to be associated positively with serum creatinine and inversely with eGFR [28]. Overall, our findings of a positive association between plasma leptin and CKD are in agreement with these previous studies; in addition, we were able to study a large multiethnic sample that includes both men and women and also adjusts for multiple confounders such as BMI, diabetes, hypertension, lipid levels, and C-reactive protein.

The main strengths of our study include its populationbased nature, inclusion of a representative multiethnic sample, adequate sample size, and the availability of data on confounders for multivariable adjustment. Furthermore, all data were collected following rigorous methodology, including a study protocol with standardized quality control checks. The main limitation of our study is the crosssectional nature of NHANES, which precludes conclusions regarding the temporal nature of the association between plasma leptin and CKD. Second, defining CKD as eGFR $<60 \mathrm{~mL} / \mathrm{min} / 1.73 \mathrm{~m}^{2}$ introduces some ascertainment bias. This bias is likely to result in under- or overestimation of odds ratios presented in this report.

In summary, in a multiethnic sample of US adults, we found that higher plasma leptin levels are associated with CKD, independent of traditional factors such as age, sex, smoking, alcohol intake, BMI, diabetes, hypertension and serum cholesterol. Our results suggest that leptin may explain part of the reported association between obesity and kidney disease. However, future prospective cohort studies are needed to confirm or refute our findings.

\section{Authors' Contributions}

All authors contributed to the intellectual development of this paper. AS had the original idea for the study, wrote the paper and is the guarantor. JX performed the statistical analyses. PM was involved in critical revisions to the manuscript.

\section{Disclosure}

"The guarantor, AS, accepts full responsibility for the work and/or the conduct of the study, had access to the data, and controlled the decision to publish."

\section{Conflicts of Interests}

There is no conflicts of interests to this manuscript.

\section{Acknowledgments}

This study was funded by an American Heart Association National Clinical Research Program Grant A. Shankar and NIH/NIEHS Grant 5R03ES018888-02 A. Shankar. 


\section{References}

[1] S. G. Wannamethee, J. Tchernova, P. Whincup et al., "Plasma leptin: associations with metabolic, inflammatory and haemostatic risk factors for cardiovascular disease," Atherosclerosis, vol. 191, no. 2, pp. 418-426, 2007.

[2] M. Carlyle, O. B. Jones, J. J. Kuo, and J. E. Hall, "Chronic cardiovascular and renal actions of leptin: role of adrenergic activity," Hypertension, vol. 39, no. 2, pp. 496-501, 2002.

[3] E. K. Jackson and P. Li, "Human leptin has natriuretic activity in the rat," American Journal of Physiology, vol. 272, no. 3, pp. F333-F338, 1997.

[4] J. E. Hall, H. L. Mizelle, D. A. Hildebrandt, and M. W. Brands, "Abnormal pressure natriuresis. A cause or a consequence of hypertension?" Hypertension, vol. 15, no. 6, pp. 547-559, 1990.

[5] G. Wolf, A. Hamann, D. C. Han et al., "Leptin stimulates proliferation and TGF- $\beta$ expression in renal glomerular endothelial cells: potential role in glomerulosclerosis," Kidney International, vol. 56, no. 3, pp. 860-872, 1999.

[6] G. Wolf, S. Chen, D. C. Han, and F. N. Ziyadeh, "Leptin and renal disease," American Journal of Kidney Diseases, vol. 39, no. 1, pp. 1-11, 2002.

[7] G. Wolf and F. N. Ziyadeh, "Leptin and renal fibrosis," Contributions to Nephrology, vol. 151, pp. 175-183, 2006.

[8] National Center for Health Statistics, Laboratory procedures used for NHANES III, http://www.cdc.gov/nchs/data/nhanes/ nhanes3/cdrom/nchs/manuals/labman.pdf.

[9] National Center for Health Statistics, Analytic and reporting guidelines: NHANES III, 1996, http://www.cdc.gov/nchs/data/ nhanes/nhanes3/nh3gui.pdf.

[10] National Center for Health Statistics, The third National Health and Nutrition Examination Survey: reference manuals and reports, 1996, http://www.cdc.gov/nchs/data/nhanes/ nh3rrm.htm.

[11] National Center for Health Statistics, Serum leptin data and documentation: NHANES III, 2002, http://www.cdc.gov/ nchs/data/cdrom/cdrom/nchs/manuals/labman.pdf.

[12] P. Bandaru and A. Shankar, "Association between plasma leptin levels and diabetes mellitus," Metabolic Syndrome and Related Disorders, vol. 9, no. 1, pp. 19-23, 2011.

[13] S. Teppala, A. Shankar, and C. Sabanayagam, "Association between IGF-1 and chronic kidney disease among US adults," Clinical and Experimental Nephrology, vol. 14, no. 5, pp. 440444, 2010.

[14] E. Selvin, J. Manzi, L. A. Stevens et al., "Calibration of serum creatinine in the National Health and Nutrition examination surveys (NHANES) 1988-1994, 1999-2004," American Journal of Kidney Diseases, vol. 50, no. 6, pp. 918-926, 2007.

[15] A. S. Levey, J. Coresh, T. Greene et al., "Expressing the modification of diet in renal disease study equation for estimating glomerular filtration rate with standardized serum creatinine values," Clinical Chemistry, vol. 53, no. 4, pp. 766$772,2007$.

[16] A. S. Levey, J. Coresh, K. Bolton et al., "K/DOQI clinical practice guidelines for chronic kidney disease: evaluation, classification, and stratification," American Journal of Kidney Diseases, vol. 39, no. 2, supplement 1, pp. S1-S266, 2002.

[17] A. V. Chobanian, G. L. Bakris, H. R. Black et al., "Seventh report of the Joint National Committee on Prevention, Detection, Evaluation, and Treatment of High Blood Pressure," Hypertension, vol. 42, no. 6, pp. 1206-1252, 2003.

[18] L. A. Viikari, R. K. Huupponen, J. S. Viikari et al., "Relationship between leptin and C-reactive protein in young Finnish adults," The Journal of Clinical Endocrinology \& Metabolism, vol. 92, no. 12, pp. 4753-4758, 2007.

[19] E. Doucet, S. St-Pierre, N. Almeras et al., "Fasting insulin levels influence plasma leptin levels independently from the contribution of adiposity: evidence from both a cross-sectional and an intervention study," The Journal of Clinical Endocrinology \& Metabolism, vol. 85, no. 11, pp. 4231-4237, 2000.

[20] A. Shankar and J. Xiao, "Positive relationship between plasma leptin level and hypertension," Hypertension, vol. 56, no. 4, pp. 623-628, 2010.

[21] J. Chen, P. Muntner, L. L. Hamm et al., "Insulin resistance and risk of chronic kidney disease in nondiabetic US adults," Journal of the American Society of Nephrology, vol. 14, no. 2, pp. 469-477, 2003.

[22] A. Shankar, L. Sun, B. E. Klein et al., "Markers of inflammation predict the long-term risk of developing chronic kidney disease: a population-based cohort study," Kidney International, vol. 80, no. 11, pp. 1231-1238, 2011.

[23] P. Z. Zimmet, V. R. Collins, M. P. de Court et al., "Is there a relationship between leptin and insulin sensitivity independent of obesity? A population-based study in the Indian Ocean nation of Mauritius. Mauritius NCD Study Group," International Journal of Obesity and Related Metabolic Disorders, vol. 22, no. 2, pp. 171-177, 1998.

[24] A. S. M. Shamsuzzaman, M. Winnicki, R. Wolk et al., "Independent association between plasma leptin and Creactive protein in healthy humans," Circulation, vol. 109, no. 18, pp. 2181-2185, 2004.

[25] E. R. Fox, E. J. Benjamin, D. F. Sarpong et al., "The relation of $\mathrm{C}$-reactive protein to chronic kidney disease in African Americans: the Jackson heart Study," BMC Nephrology, vol. 11, no. 1 , article 1, 2010.

[26] S. Rudberg and B. Persson, "Serum leptin levels in young females with insulin-dependent diabetes and the relationship to hyperandrogenicity and microalbuminuria," Hormone Research, vol. 50, no. 6, pp. 297-302, 1998.

[27] I. G. Okpechi, M. D. Pascoe, C. R. Swanepoel, and B. L. Rayner, "Microalbuminuria and the metabolic syndrome in non-diabetic black Africans," Diabetes and Vascular Disease Research, vol. 4, no. 4, pp. 365-367, 2007.

[28] I. G. Okpechi, B. L. Rayner, L. Van Der Merwe et al., "Genetic variation at selected SNPs in the leptin gene and association of alleles with markers of kidney disease in a Xhosa population of South Africa," PLoS ONE, vol. 5, no. 2, Article ID e9086, 2010. 


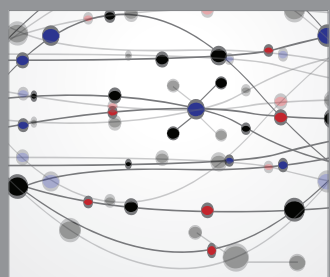

The Scientific World Journal
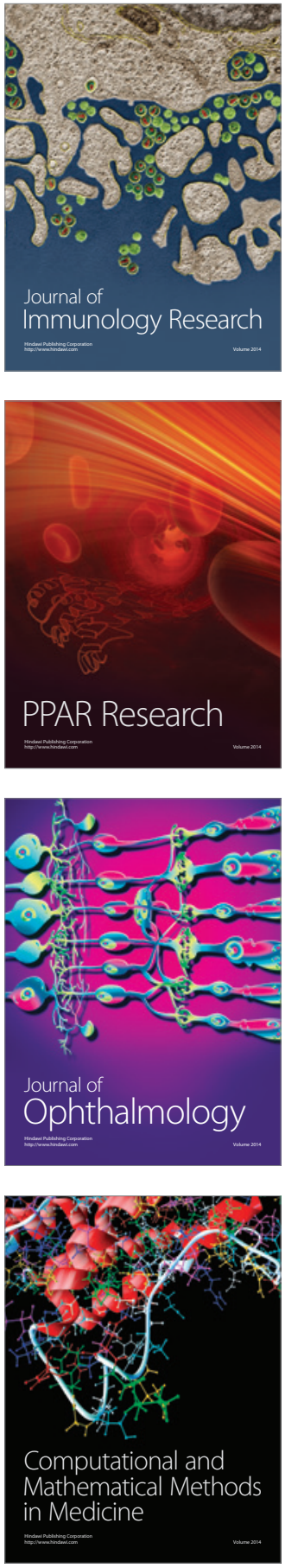

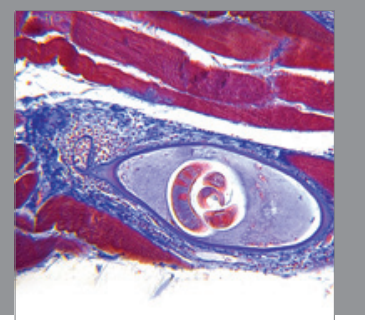

Gastroenterology

Research and Practice
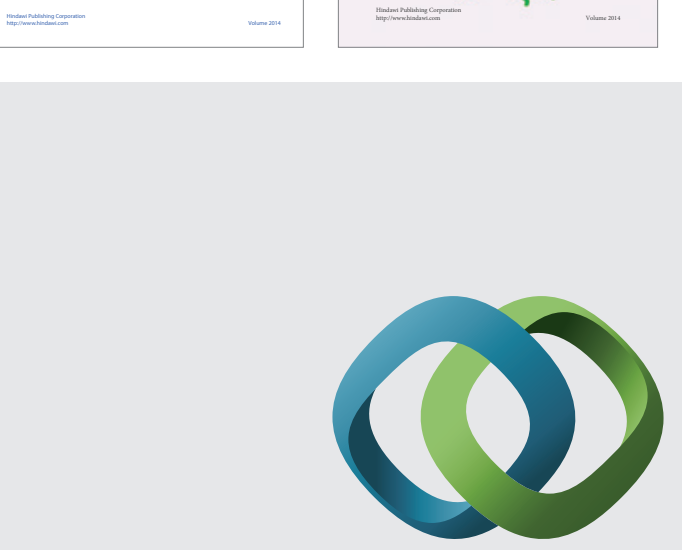

\section{Hindawi}

Submit your manuscripts at

http://www.hindawi.com
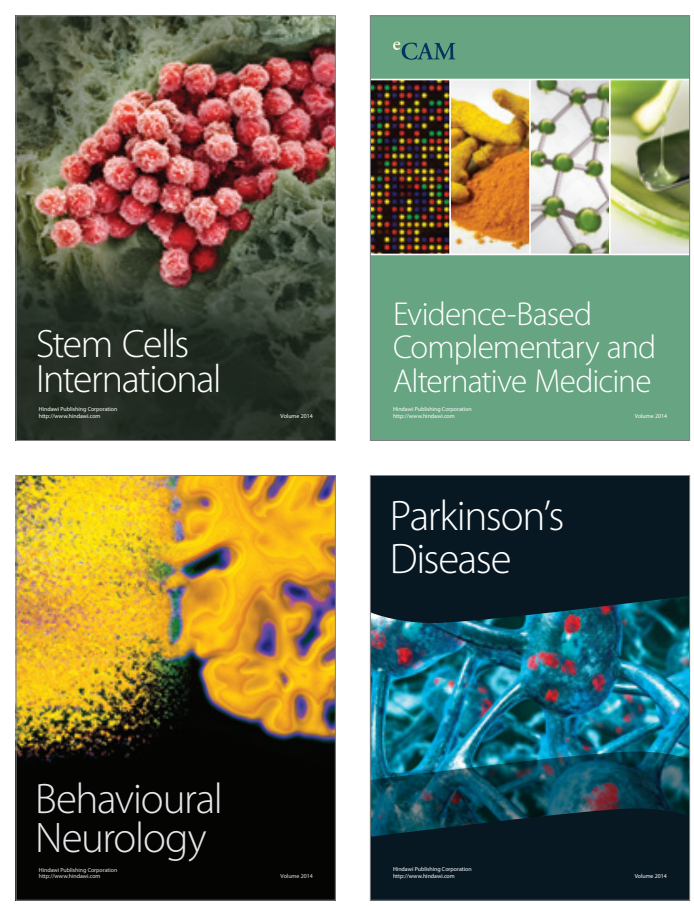

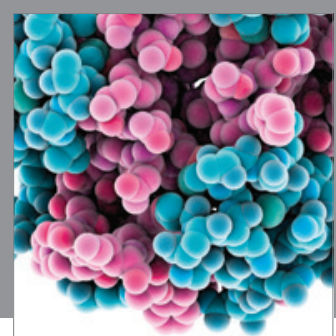

Journal of
Diabetes Research

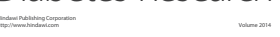

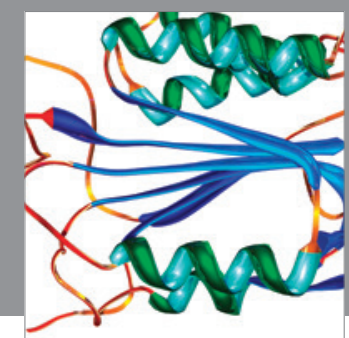

Disease Markers
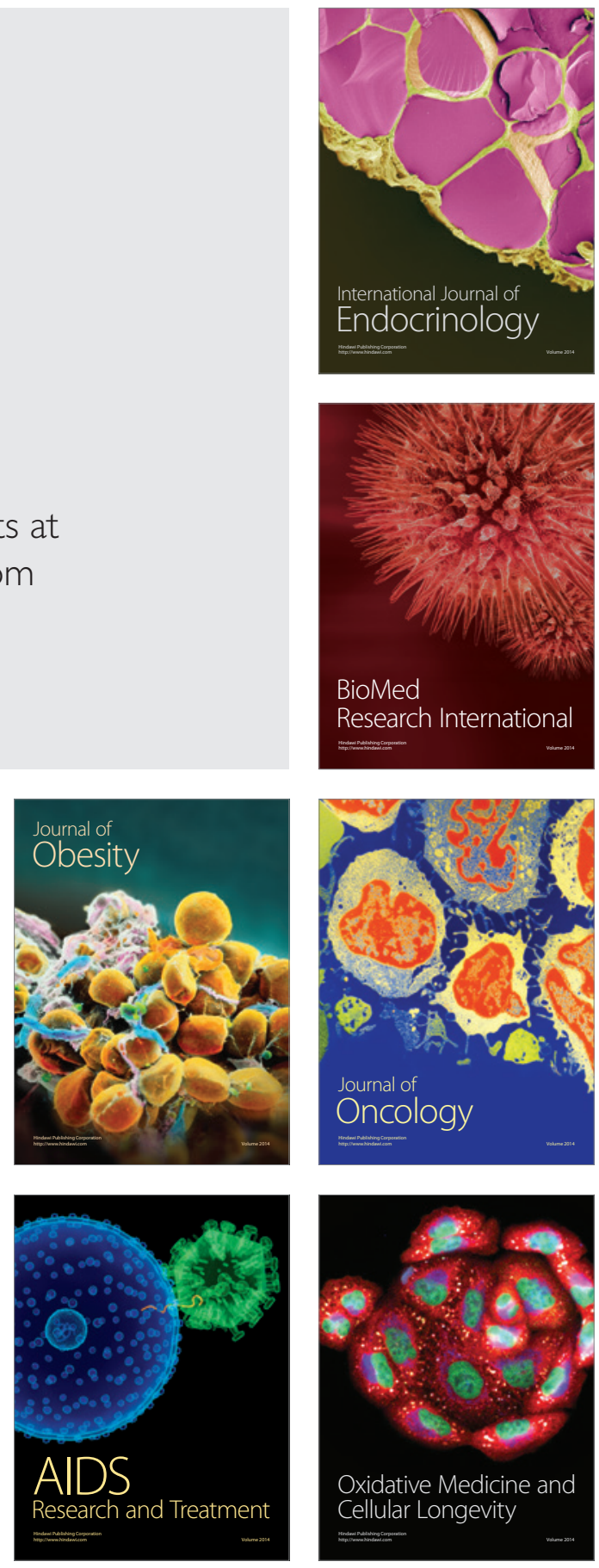